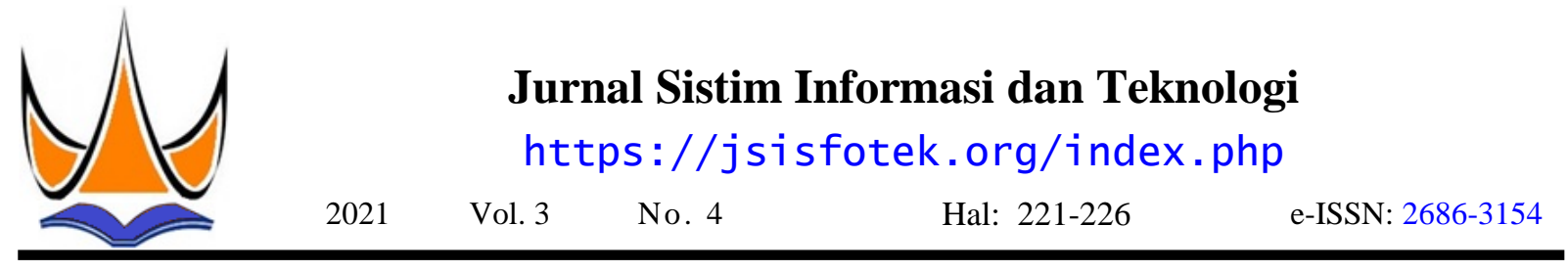

\title{
Sistem Pakar dalam Mengidentifikasi Gejala Stroke Menggunakan Metode Naive Bayes
}

\author{
Fajri Karim ${ }^{1 凶}$, Gunadi Widi Nurcahyo ${ }^{2}$, Sumijan $^{3}$ \\ ${ }^{1,2,3}$ Universitas Putra Indonesia YPTK Padang
}

fajrikarim@gmai1.com

\begin{abstract}
Stroke is a disease caused by brain damage caused by disruption of the blood supply to the brain. At this time in general, people are still not very familiar with how this stroke disease or do not realize the symptoms that may have appeared from the start. People also tend to be hesitant to visit the hospital to check their symptoms and feel they are delaying further examinations. This is certainly a scourge that continues to make the number of strokes increase. In assisting the community in identifying stroke disease, an expert system is needed that is able to identify the type of stroke based on the symptoms felt. The data used in this study were obtained from Brain Hospital. Dr. Drs. M. Hatta Bukittinggi which was later developed into a website-based system using the PHP Framework Laravel programming language and MySQL as the database. The system is built based on the Naive Bayes method which is one of the Expert System methods that has a high accuracy value. The use of this system is expected to be able to provide knowledge to the public about the symptoms that might lead to what type of stroke the user might suffer, so that the user can use the results of the system as a reference to visit the hospital and immediately get more targeted help. This system can perform calculations that match the results of the doctor's diagnosis with an accuracy value of $100 \%$ in identifying the type of stroke from 10 data samples used.
\end{abstract}

Keywords: Expert System, Identification, Symptom, Stroke, Naive Bayes.

\begin{abstract}
Abstrak
Penyakit stroke merupakan penyakit yang disebabkan oleh kerusakan otak yang diakibatkan gangguan dari suplai darah menuju otak. Pada saat ini umumnya masyarakat masih belum begitu mengenal bagaimana penyakit stroke ini ataupun tidak menyadari gejala yang mungkin sudah muncul sedari awal. Masyarakat juga cendrung masih ragu mengunjungi rumah sakit untuk melakukan pemeriksaan terhadap gejala yang dialaminya dan merasa menunda pemeriksaan lebih lanjut. Hal ini tentu menjadi momok yang terus membuat angka penyakit stroke semakin meningkat. Dalam membantu masyarakat dalam mengidentifikasi penyakit stroke, maka diperlukan sebuah Sistem Pakar yang mampu melakukan identifikasi jenis penyakit stroke berdasarkan gejala yang dirasakan. Data yang digunakan pada penelitian ini didapat dari Rumah Sakit Otak Dr. Drs. M. Hatta Bukittinggi yang kemudian dikembangkan ke dalam bentuk sistem berbasis website menggunakan bahasa pemrograman PHP Framework Laravel dan MySQL sebagai databasenya. Sistem dibangun berdasarkan metode Naive Bayes yang merupakan salah satu metode Sistem Pakar yang memiliki nilai akurasi yang tinggi. Penggunaan sistem ini diharapkan mampu memberikan pengetahuan kepada masyarakat akan gejala yang mungkin mengarah ke jenis penyakit stroke apa yang mungkin diderita oleh user, sehingga user dapat menjadikan hasil sistem tersebut sebagai acuan untuk mengunjungi rumah sakit dan segera mendapatkan pertolongan yang lebih terarah. Sistem ini dapat melakukan perhitungan yang cocok dengan hasil diagnosa dokter dengan nilai akurasi sebesar $100 \%$ dalam mengidentifikasi jenis penyakit stroke dari 10 sampel data yang digunakan.
\end{abstract}

Kata kunci: Sistem Pakar, Identifikasi, Gejala, Stroke, Naive Bayes.

(C) 2021 JSisfotek

\section{Pendahuluan}

Penyakit stroke merupakan penyakit yang disebabkan oleh kerusakan otak akibat gangguan dari suplai darah menuju otak. Penyakit stroke memiliki catatan kematian tertinggi kedunia diseluruh dunia. Penyakit stroke dapat menyerang tanpa memandang usia ataupun jenis kelamin yang datang secara tiba-tiba dan memiliki angka kematian cukup tinggi [1].

Pada saat ini masyarakat masih belum begitu mengenal bagaimana penyakit stroke ini ataupun tidak menyadari gejala yang mungkin sudah muncul sedari awal.
Terlebih lagi masyarakat pada umumnya ragu untuk mengunjungi rumah sakit hanya untuk sekedar menanyakan gejala yang dialaminya. Hal ini terus menjadi momok yang membuat angka penyakit stroke semakin melonjak tajam dan terus menghantui kehidupan masyarakat. Terdapat berbagai faktor yang membuat angka penyakit stroke terus bertambah, diantaranya gaya hidup masyarakat pada saat ini yang cenderung tidak terkontrol terhadap makan-makanan cepat saji, kerja berlebihan, stress, kurang berolahraga, merokok, penggunaan obat yang tidak sesuai dan faktor lainnya [2]. 
Perkembang zaman dan peradaban manusia yang Nearest Neighbor pada penelitian tersebut dari 40 data semakin maju dengan adanya teknologi dan juga ilmu uji yang digunakan. Hal ini dipengaruhi oleh kesehatan dapat dikolaborasikan menjadi sesuatu yang preprocessing seperti melakukan stemming kata [9].

dapat bermanfaat bagi masyarakat umum. Salah satunya adalah Sistem Pakar yang dapat membantu dalam mengidentifikasi gejala awal penyakit. Sistem ini nantinya diharapkan user/pasien bisa melakukan penanganan awal pada dirinya sendiri [3].

Berdasarkan hasil penelitian terhadap diagnosis penyakit jantung menggunakan data mining. Diketahui algoritma metode Naive Bayes memiliki 4 kemungkinan hasil output. Hal itu berdasarkan pengujian metode Naive Bayes menggunakan dataset Sistem Pakar menjadi terobosan yang membantu sebanyak 303 maka didapatkan hasil akurasi sebesar masyarakat sebagai asisten pribadi dan menuntut 86\%[10].

pengguna sistem untuk menyelesaikan permasalahan yang sedang dihadapi. Penyelesaian masalah tersebut menggunakan pengetahuan dari seorang pakar yang didapatkan pengalaman pakar itu sendiri. Pengetahuan itu disimpan dalam komputer serta dilakukan perhitungan yang tepat untuk menarik kesimpulan suatu permasalahan [4].

Dari hasil simulasi dan penelitian dapat dievaluasi bahwa metode Naive Bayes ini hanya dapat mengubah himpunan entri dengan jumlah yang terbatas pada fitur dan meningkatkan efisiensi klasifikasi daripada semua fitur yang digunakan. Selain itu, penggunaan metode Naive Bayes untuk pemilihan fitur dalam kumpulan data dengan besar sejumlah fitur juga dapat dipelajari Naive Bayes merupakan salah satu Sistem Pakar untuk mewujudkan fitur Naive Bayes yang berbeda dengan jenis Bayesian Network yang paling sering dalam pemilihan fitur. Itu mungkin juga termasuk digunakan untuk mengklasifikasikan. Metode Naive teknik lain dari data mining untuk membuat klasifikasi Bayes memili nilai akurasi tertinggi hingga 99,51\% yang akurat dan efektif secara komputasi untuk aplikasi dari metode Sistem Pakar lainnya. Bayesian Network medis [11].

mengasumsikan bahwa kemunculan atribut yang ada pada suatu kelas tidak terkait dengan keberadaan atribut lainnya yang membuatnya lebih menguntungkan dan memiliki efisiensi lebih [5].

Setiap pasien dapat memprediksi penyakit tergantung pada gejalanya. Nilai prediksi tersebut dihitung melalui klasifikasi Naive Bayes yang bertindak sebagai merupakan algoritma sederhananya. Secara pengklasifikasi dan memberikan keluaran nilai keseluruhan, akurasi, sensitivitas, spesifisitas $100 \%$ probabilistik. Naive Bayes dapat mengklasifikasikan dicapai dalam penelitian ini [12].

penyakit dengan mudah apakah pasien tersebut memiliki kemungkinan penyakit yang dipilih atau tidak. Selain itu dapat membantu tenaga kesehatan saat membuat keputusan dengan $80 \%$ keakuratan sesuai dengan hasil dokter [6].

Pada penelitian kegagalan jantung kongestif menggunakan metode Naive Bayes bekerja sangat baik untuk dataset kecil yang sesuai dengan penelitian ini, karena jumlah dataset yang cukup terbatas. Keuntungan utama lain dari Naive Bayes yaitu melebihi algoritma acak kompetitif lainnya seperti KNN \& SVM yang

Dapat juga dilihat pada penelitian yang menggunakan 30 data latih dan 76 data uji medical record pengguna obat hiperkolesterolemia di RSUD Tugurejo Semarang. Dengan variabelnya adalah gejala umum dan beberapa obat hiperkolesterolemia. Didapatkan pemilihan sistem Dari pembahasan penelitian yang dilakukan untuk obat hiperkolesterolemia dengan keakuratan 96,05\% menarik kesimpulan melalui Sistem Pakar penyakit [13]. Penerapan metode Naive Bayes Classifier pada lambung dengan menggunakan metode Naive Bayes. penelitian mengenai gejala awal penyakit Covid-19 Pada Sistem Pakar tersebut pengguna dapat melakukan pada pasien. Dapat ditelusuri bahwa hasil diagnosis konsultasi dengan menjawab beberapa pertanyaan yang menjadi lebih baik yang disertai dengan penjelasan dari ada. Semakin banyak pengguna tersebut menjawab pengetahuan seorang pakar. Pengujian Sistem Pakar pertanyaan yang ada maka tingkat persentase hasilnya yang dilakukan oleh pasien untuk diagnosa Covid-19 akan semakin akurat [7].

Algoritma Naive Bayes lebih akurat dibanding diperoleh dari hasil suatu penyakit berdasarkan fakta yang diperoleh [14].

alogitma lainnya ini terbukti dalam penelitian Pada penelitian mendeteksi dini penyakit jantung dan klasifikasi dataset dermatalogi. Klasifikasi dataset diabetes berdasarkan nilai laporan pengujian. tersebut berdasarkan dari beberapa penyakit Penggunaan algoritma Naive Bayes memberika hasil dermatologi yang berbeda dengan nilai akurasi sebesar yang akurat. Dengan demikian sistem dapat melakukan 99,31\%. Oleh karna itu Metode Naive Bayes cocok prediksi penyakit jantung dan melakukan diagnosis untuk klasifikasi data dalam bidang medis maupun data medis apakah ada kemungkinan penyakit jantun bidang lainnya [8].

Salah satu perbandingan penerapan metode Naive Bayes dan metode K-Neares Neighbor terhadap klasifikasi artikel jurnal Indonesia. Dapat diketahui metode Naive Bayes lebih unggul dari metode Katau diabates [15]. Dari hasil penulisan artikel metode Sistem Pakar yang ada pada saat ini. Salah satu aplikasinya tentang pembuatan aplikasi diagnosis gangguan hiperaktif pada anak yang berbasiskan website. Aplikasi tersebut menghasilkan presentase angka dan informasi ke masyarakat agar lebih mengerti 
mengenai gejala-gejala gangguan hiperaktif yang Data Jenis penyakit stroke yang telah diberi kode untuk terjadi pada anak [16]. Penelitian multivariasi Naive mewakili penyakit tersebut dapat dilihat pada Tabel 1.

Bayes Classifier yang dilakukan pada sebuah model dalam memprediksi probabilitas mengamati sinyal impulsif pada gempa bumi. Diketahui bahwa Naive Bayes dapat diterapkan pada dataset. Dataset kemudian dibagi menjadi dua kategori menggunakan informasi dari jenis kesalahan yang terjadi [17].

\section{Metodologi Penelitian}

Metode Sistem Pakar yang digunakan pada penelitian ini adalah metode Naive Bayes yang didasarkan pada penelitian terdahulu dirasa cocok untuk membangun sebuah aplikasi Sistem Pakar dengan nilai akurasi yang cukup tinggi. Penelitian yang dilakukan menggunakan aplikasi berbasis website yang dapat digunakan dalam identifikasi jenis penyakit stroke. Tahapan arsitektur yang ada di metode Naive Bayes ini dapat dilihat pada Gambar 1 .

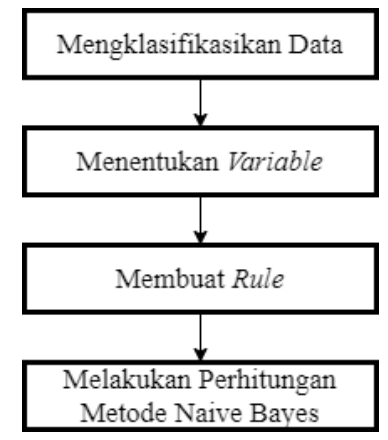

Gambar 1. Arsitektur Naive Bayes diatas merupakan tahapan penelitian GI6005 menggunakan metode Naive Bayes yang dapat dirincikan sebagai berikut :

\subsection{Mengklasifikasikan Data}

Data diperoleh dari konsultasi pasien di Rumah Sakit Otak Dr. Drs. M. Hatta Bukittinggi selama 7 bulan (Januari-Juli) pada tahun 2021. Data tersebut akan diklasifikan menjadi beberapa bagian yaitu data jenis penyakit stroke, data gejala penyakit stroke dan data rule dari seorang pakar. Pada jenis penyakit terdapat 2 jenis penyakit stroke secara general yaitu stroke hemorogik dan stroke iskemik. Selanjutnya data gejala penyakit stroke diperoleh data sebanyak 13 gejala, hal ini berdasarkan pengujian / pemeriksaan diagnosa klinis awal yang dilakukan diluar dari pemeriksaan Data gejala penyakit stroke diberi kode yang terdiri dari Magnetic Resonance Imaging (MRI) ataupun 6 digit. Kode tersebut terdiri dari 1 digit awal yaitu Computerized Tomography Scan (CT Scan) yang huruf G (Gejala), 2 digit selanjutnya I6 kode ICD menandai seseorang menderita penyakit stroke.

\subsection{Menentukan Variable}

Data yang telah diklasifikasikan selanjutnya akan diberi variable atau kode agar dapat mempermudah dalam Jenis penyakit stroke memiliki beberapa gejala yang pengembangan sistem. Terdapat 2 bagian yang akan sama dan ada juga yang memiliki gejala yang berbeda. diberi kode yaitu data jenis penyakit stroke dan data Pada saat menentukan jenis penyakit stroke secara gejala penyakit stroke. Setiap kode diberikan akurat menggunakan aplikasi Sistem Pakar, maka merupakan kombinasi dari huruf dan angka.
Tabel 1. Data Jenis-Jenis Penyakit Stroke

\begin{tabular}{ll}
\hline Kode Penyakit & Jenis Penyakit Stroke \\
\hline RSOI601 & Stroke Hemoragik \\
RSOI602 & Stroke Iskemik \\
\hline
\end{tabular}

Data jenis penyakit diberi kode yang terdiri dari 7 digit. Kode tersebut terdiri dari 3 digit awal huruf yaitu RSO singkatan dari Rumah Sakit Otak, 2 digit berikutnya yaitu I6 yang merupakan kode penyakit stroke dari salah satu kode ICD (International Classification of Diseases) dalam klasifikasi penyakit internasional yang dikelola organisasi kesehatan dunia (WHO) dan 2 digit terakhir yaitu nomor urutan jenis penyakit stroke.

Data gejala penyakit stroke sebanyak 13 data gejala yang telah diberi kode untuk mewakili gejala tersebut yang dapat dilihat pada Tabel 2.

Tabel 2. Data Gejala Penyakit Stroke

\begin{tabular}{ll}
\hline Kode Gejala & Nama Gejala \\
\hline \multirow{2}{*}{ GI6001 } & Lemah / berat di salah satu bagian tubuh ataupun ada \\
& rasa kebas / kesemutan disebagian tubuh. \\
& Kesulitan saat berbicara (pelo atau tidak bisa \\
& berbicara jelas), Senyum tidak simetris, Kesulitan \\
GI6002 & dalam menggenggam seuatu, Gangguan penglihatan / \\
& sensitif terhadap cahaya, Kesulitan memahami \\
pembicaraan.
\end{tabular}

GI6003 sering melamun / sering mengantuk / sering tertidur tetapi dapat sadar kembali jika dirangsang (dibangungkan) atau merespon terhadap nyeri.

Mengalami kondisi tidak sadarkan diri atau koma. Mengalami muntah-muntah dalam 2 jam terakhir. Terdapat nyeri / sakit pada kepala dalam 2 jam terakhir

Terdapat salah satu tanda dari Atheroma yaitu Angina Pectoris (nyeri pada dada seperti tertekan atau terasa berat), Claudicatio Intermitten (ketidaknyamanan pada otot ekstremitas bawah) dan Diabetes Mellitus.

Tekanan diastolik lebih dari 90mmHg / Hipertensi

Masih terdapat gerakan Dorsofleksi pada ibu jari kaki maupun mekarnya jari-jari kaki saat melakukan pengujian Refleks Babinski.

Mengalami kejang-kejang.

Sakit / nyeri / pegal pada bagian badan tertentu.

Nafsu makan berkurang / susah makan / susah

menelan.

Daya ingat berkurang / sering lupa. penyakit stroke dan 3 digit terakhir adalah nomor urutan gejala penyakit stroke.

\subsection{Membuat Rule}

diperlukan sebuah aturan (rule) dan aturan tersebut 
berisi nilai-nilai gejala terhadap jenis penyakitnya $\mathrm{J}(\mathrm{QXE} \mid \mathrm{BNV})$ merupakan probabalitas berdasarkan sehingga menjadi kaidah acuan dalam merancang kondisi.

sebuah sistem. Rule ini nantinya akan mewakili seorang pakar dalam menentukan sebuah keputusan. Keputusan yang dihasilkan pada sistem tersebut akan menunjukkan jenis penyakit apa yang mungkin diderita oleh user melalui persentase tertinggi dari jenis

d. Hitung nilai probabilitas total untuk setiap penyakit yang ada dengan menggunakan rumus :

$$
P(T)=\frac{h}{H} \times 100 \%
$$

penyakit stroke yang ada. Hasil persentase tersebut Di mana P merupakan probabilitas terjadinya peristiwa, didasarkan kepada gejala-gejala yang dipilih oleh user $\mathrm{T}$ adalah peristiwa, $\mathrm{h}$ merupakan jumlah kejadian itu sendiri yang terpadat pada aplikasi Sistem Pakar. berhasil dan H merupakan jumlah semua kejadian.

Rule tersebut dapat dilihat pada Tabel 3.

Tabel 3. Rule Penyakit dan Gejala Stroke

\begin{tabular}{lcc}
\hline \multirow{2}{*}{ Kode Gejala } & \multicolumn{2}{c}{ Kode Jenis Penyakit } \\
\cline { 2 - 3 } & RSOI601 & RSOI602 \\
\hline GI6001 & 1,0 & 1,0 \\
GI6002 & 1,0 & 1,0 \\
GI6003 & 0,5 & 0,3 \\
GI6004 & 1,0 & 0,0 \\
GI6005 & 0,5 & 0,3 \\
GI6006 & 1,0 & 0,3 \\
GI6007 & 1,0 & 0,7 \\
GI6008 & 0,5 & 0,5 \\
GI6009 & 0,3 & 1,0 \\
GI6010 & 0,5 & 0,5 \\
GI6011 & 0,5 & 0,5 \\
GI6012 & 0,5 & 0,5 \\
GI6013 & 0,5 & 0,5 \\
\hline
\end{tabular}

\subsection{Melakukan Perhitungan Metode Naive Bayes}

Untuk melakukan perhitungan metode Naive Bayes terdapat beberapa langkah yang harus ditentukan yaitu :

a. Tentukan nilai dari Naive Bayes Classifier (nc) untuk setiap class yang ada yaitu didapatkan dari nilai pada Tabel 3 sesuai dengan penyakitnya.

b. Hitung nilai probabilitas dengan rumus [18] :

$$
J(Q X E \mid B N V)=\frac{J(B N V \mid Q X E) \times J(Q X E)}{J(B N V)}
$$

Di mana nilai QXE adalah hipotesis khusus (benar atau salah), BNV merupakan bukti yang telah diamati, $\mathrm{J}(\mathrm{QXE} \mid \mathrm{BNV})$ adalah probabilitas hipotesis berdasarkan kondisi atau disebut juga probabilitas posterior, $\mathrm{J}(\mathrm{BNV} \mid \mathrm{QXE})$ merupakan probabilitas $\mathrm{BNV}$ berdasarkan hipotesis QXE, J(QXE) merupakan probabilitas QXE disimpulkan sebelum bukti baru atau disebut juga probabilitas prior, J(BNV) adalah probabilitas marginal BNV dalam semua hipotesis yang mungkin.

c. Hitung nilai probabilitas total untuk setiap penyakit yang ada dengan menggunakan rumus :

$$
J(B N V) x\left[J\left(Q X E_{1} \mid B N V_{1}\right) x \ldots x J\left(Q X E_{f} \mid B N V_{k}\right]\right.
$$
Di mana J(BNV) merupakan probabilitas marginal
BNV dalam semua hipotesis yang mungkin dan $J_{1}(G I 6008 \mid R S O I 601)=\frac{(0,5+13) x 0,5}{(1+13)}=0,482$

\section{Hasil dan Pembahasan}

Pengujian perhitungan menggunakan metode Naive Bayes diterapkan pada salah satu contoh kasus konsultasi pasien di Rumah Sakit Otak Dr. Drs. M. Hatta Bukittinggi. Gejala yang dirasakan pasien tersebut adalah kontrol anggota gerak kanan berat (GI6001), tekanan diastolik 95mmHg (GI6008), nyeri kepala / pusing (GI6006) dan mual sampai muntah (GI6005). Dari gejala tersebut, maka perhitungan metode Naive Bayes adalah sebagai berikut:

a. Menentukan nilai nc untuk setiap class.

Penyakit ke-1 : Penyakit Stroke Hemorogik

$\mathrm{n}=1$

$\mathrm{D}=1 / 2=0,5$

$\mathrm{S}=10$

GI6001. $n c=1,0$

GI6008. $n c=0,5$

GI6006. $n c=1,0$

GI6005. $n c=0,5$

RSOI601.nc $=0,5$

$\mathrm{n}=1$

$\mathrm{D}=1 / 2=0,5$

$\mathrm{S}=10$

GI6001. $n c=1,0$

GI6008. $n c=0,5$

GI6006. $n c=0,3$

GI6005. $n c=0,3$

RSOI602.nc $=1,0$

Penyakit ke-1 : Penyakit Stroke Hemorogik

$J_{1}(G I 6001 \mid R S O I 601)=\frac{(1+13) \times 0,5}{(1+13)}=0,5$
Penyakit ke-2 : Penyakit Stroke Iskemik

b. Menghitung nilai probabilitas. 


$$
\begin{aligned}
& J_{1}(G I 6006 \mid R S O I 601)=\frac{(1+13) \times 0,5}{(1+13)}=0,5 \\
& J_{1}(G I 6005 \mid R S O I 601)=\frac{(0,5+13) \times 0,5}{(1+13)}=0,482 \\
& J(B N V)=\frac{(0,5+13) \times 0,5}{(1+13)}=0,482
\end{aligned}
$$

Penyakit ke-2 : Penyakit Stroke Iskemik

$$
\begin{aligned}
& J_{2}(\text { GI6001|RSOI602 })=\frac{(1+13) \times 0,5}{(1+13)}=0,5 \\
& J_{2}(G I 6008 \mid R S O I 602)=\frac{(0,5+13) \times 0,5}{(1+13)}=0,482 \\
& J_{2}(G I 6006 \mid R S O I 602)=\frac{(0,3+13) \times 0,5}{(1+13)}=0,475 \\
& J_{2}(G I 6005 \mid R S O I 602)=\frac{(0,3+13) \times 0,5}{(1+13)}=0,475 \\
& J(B N V)=\frac{(1+13) \times 0,5}{(1+13)}=0,5
\end{aligned}
$$

c. Menghitung nilai probabilitas total setiap penyakit. Penyakit ke-1 : Penyakit Stroke Hemorogik $J(B N V) x[(G I 6001 \mid R S O I 601) x(G I 6008 \mid R S O I 601) x$
(GI6006|RSOI601)x(GI6005|RSOI601)]

$$
=0,482 \times[0,5 \times 0,482 \times 0,5 \times 0,482]=0,027995
$$

Penyakit ke-2 : Penyakit Stroke Iskemik $J(B N V) x[(G I 6001 \mid R S O I 602) x(G I 6008 \mid R S O I 602) x$ (GI6006|RSOI602)x(GI6005|RSOI602)] $=0,5 \times[0,5 \times 0,482 \times 0,475 \times 0,475]=0,027188$

d. Menentukan nilai terbesar dari perhitungan probabilitas total setiap penyakit. Hasil perhitungan probabilitas total dapat dilihat pada tabel 4.

Tabel 4. Hasil Probabilitas Total

\begin{tabular}{clr}
\hline Kode Penyakit & Jenis Penyakit Stroke & Nilai Probabilitas \\
\hline RSOI601 & Stroke Hemoragik & 0,027995 \\
RSOI602 & Stroke Iskemik & 0,027188 \\
\hline
\end{tabular}

Berdasarkan hasil yang ada pada Tabel 4, maka nilai terbesar dari hasil probabilitas total terdapat pada jenis

\begin{tabular}{|c|c|c|c|c|}
\hline \multirow{2}{*}{ Nama Pasien } & \multirow{2}{*}{ Gejala } & \multicolumn{2}{|c|}{ Hasil Diagnosa } & \multirow{2}{*}{ Nilai Akurasi } \\
\hline & & Pakar & Sistem & \\
\hline \multirow{3}{*}{ Pasien 1} & 1. Anggota gerak kanan berat & \multirow{3}{*}{ Stroke Iskemik } & \multirow{3}{*}{ Stroke Iskemik } & \multirow{3}{*}{1} \\
\hline & 2. Bicara pelo & & & \\
\hline & 3. Tekanan diastolik $96 \mathrm{mmHg}$ & & & \\
\hline \multirow{4}{*}{ Pasien 2} & 1. Anggota gerak kiri berat & \multirow{4}{*}{ Stroke Iskemik } & \multirow{4}{*}{ Stroke Iskemik } & \multirow{5}{*}{1} \\
\hline & 2. Bicara pelo & & & \\
\hline & 3. Menelan terganggu & & & \\
\hline & 4. Daya ingat menurun & & & \\
\hline \multirow{3}{*}{ Pasien 3} & 1. Anggota gerak kanan berat & \multirow{4}{*}{ Stroke Hemorogik } & \multirow{4}{*}{ Stroke Iskemik } & \\
\hline & 2. Mulut mencong / tidak simetris & & & \multirow[t]{3}{*}{0} \\
\hline & 3. Gangguan menelan & & & \\
\hline \multirow{4}{*}{ Pasien 4} & 1. Anggota gerak kiri berat dan kebas & & & \\
\hline & 2. Pegal pada pundak & \multirow[t]{3}{*}{ Stroke Iskemik } & \multirow[t]{3}{*}{ Stroke Iskemik } & \multirow[t]{3}{*}{1} \\
\hline & 3. Sering lupa & & & \\
\hline & 1. Anggota gerak kanan berat & & & \\
\hline \multirow[t]{2}{*}{ Pasien 5} & 2. Pandangan kabur & \multirow{2}{*}{ Stroke Iskemik } & \multirow{2}{*}{ Stroke Iskemik } & \multirow[t]{2}{*}{1} \\
\hline & 3. Nyeri pinggang & & & \\
\hline \multirow{3}{*}{ Pasien 6} & 1. Anggota gerak kanan lemah & \multirow{3}{*}{ Stroke Iskemik } & \multirow{3}{*}{ Stroke Iskemik } & \multirow{3}{*}{1} \\
\hline & 2. Nafsu makan berkurang & & & \\
\hline & 1. Anggota gerak kanan berat & & & \\
\hline \multirow{3}{*}{ Pasien 7} & 2. Kepala nyeri & \multirow[t]{3}{*}{ Stroke Hemoragik } & \multirow[t]{3}{*}{ Stroke Hemoragik } & 1 \\
\hline & 3. Mual sampai muntah & & & \\
\hline & 1. Anggota gerak kanan berat & & & \\
\hline Pasien 8 & 2. Kepala pusing / sakit & Stroke Hemoragik & Stroke Hemoragik & 1 \\
\hline & 3. Daya ingat menurun & & & \\
\hline & 1. Anggota gerak kiri berat & & & \\
\hline Pasien 9 & 2. Lidah berat saat bicara & Stroke Iskemik & Stroke Iskemik & 1 \\
\hline & 3. Nafsu makan berkurang & & & \\
\hline & 1. Anggota gerak kanan berat sejak 5 jam lalu & & & \\
\hline Pasien 10 & 2. Lidah terasa berat & Stroke Iskemik & Stroke Hemorogik & 0 \\
\hline & 3. Kepala sakit & & & \\
\hline
\end{tabular}
penyakit stroke hemorogik dengan nilai 0,027995. Dari contoh kasus ini, maka pasien tersebut dikatakan menderita penyakit stroke hemorogik. Perbandingan hasil konsultasi lainnya menggunakan 10 sampel data konsultasi pasien antara aplikasi Sistem Pakar dengan hasil diagnosa dokter dari Rumah Sakit Otak Dr. Drs. M. Hatta, dapat dilihat pada Tabel 5.

Tabel 5. Perbandingan Hasil Konsultasi 
Pada Tabel 5 dapat dilihat kecocokan hasil yaitu nilai akurasi 1 berarti menyatakan cocok dan 0 berarti menyatakan tidak cocok. Keakuratan metode Naive Bayes dapat dihitung dengan menggunakan rumus (3). Berdasarkan rumus tersebut didapatkan nilai akurasi metode Naive Bayes sebesar $80 \%$.

\section{Kesimpulan}

Penerapan metode Naive Bayes pada aplikasi Sistem Pakar berbasis website dalam mengidentifikasi jenis penyakit stroke memiliki nilai akurasi sebesar $80 \%$ dengan diagnosa dokter dari Rumah Sakit Otak Dr. Drs. M. Hatta Bukittinggi. Hal ini didapat dari 10 sampel data yang digunakan untuk menentukan jenis penyakit stroke yang mungkin diderita oleh user/pasien. Keakuratan dalam menentukan jenis penyakit stroke tidak sepenuhnya bisa dinilai dari gejala klinis awal yang dirasakan pasien, satu-satunya kepastian jenis penyakit stroke secara akurat hanya bisa dipastikan melalui pemeriksaan CT Scan ataupun MRI. Aplikasi ini dapat memberikan user informasi berupa kemungkinan dirinya menderita jenis penyakit stroke dengan nilai angka probabilitas berdasarkan gejala yang dipilih. Informasi ini akan berguna bagi user sebagai acuan untuk segera datang ke rumah sakit dan mendapatkan permeriksaan lebih lanjut yang lebih terarah.

\section{Daftar Rujukan}

[1] Byna, A., \& Basit, M. (2020). Penerapan Metode Adaboost untuk Mengoptimasi Prediksi Penyakit Stroke dengan Algoritma Naive Bayes. Jurnal Sisfokom (Sistem Informasi Dan Komputer, 9(3), 407-411. http://doi.org/10.32736/sisfokom.v9i3.1023

[2] Alchuriyah, S., \& Wahjuni, C. U. (2016). The Factors that Affect Stroke at Young Age in Brawijaya Hospital Surabaya. Jurnal Berkala Epidemiologi, 4(1), https://doi.org/10.20473/jbe.v4i1.2016.62-73

[3] Luthvan, D. (2019). Diagnosis Penyakit Diabetes pada Masyarakat Awam Menggunakan Metode Backward Chaining. Jurnal Sistim Informasi Dan Teknologi, 1(4), 43-51. https://doi.org/10.35134/jsisfotek.v1i4.14

[4] Yuliyana, Y., \& Sinaga, A. S. R. M. (2019). Sistem Pakar Diagnosa Penyakit Gigi Menggunakan Metode Naive Bayes. Fountain of Informatics Journal, 4(1), 19. https://doi.org/10.21111/fij.v4i1.3019

[5] Geetha, G., \& Prasad, K. Mohana. (2020). Prediction of Diabetics using Machine Learning. IJITEE (International Journal of Innovative Technology and Exploring Engineering), 8(5), 1119-1124. https://doi.org/10.35940/ijrte.e6290.018520

[6] Zohra, F. T. (2020). Prediction of Different Diseases and Development of a Clinical Decision Support System using Naive Bayes Classifier. International Journal for Research in Applied
Science and Engineering Technology, 8(5), 8-13. https://doi.org/10.22214/ijraset.2020.5002

[7] Minarni, M., \& Irawan, P. (2019). Implementasi Metode Naive Bayes untuk Diagnosa Penyakit Lambung. Jurnal TeknoIf, 7(2), 115. https://doi.org/10.21063/jtif.2019.v7.2.115-123

[8] Sudha, M., \& Poorva, B. (2019). Predictive Tool for Dermatology Disease Diagnosis using Machine Learning Techniques. IJITEE (International Journal of Innovative Technology and Exploring Engineering), 8(9), 355-360. https://doi.org/10.35940/ijitee.g5376.078919

[9] Devita, R. N., Herwanto, H. W., \& Wibawa, A. P. (2018). Perbandingan Kinerja Metode Naive Bayes dan K-Nearest Neighbor untuk Klasifikasi Artikel Berbahasa indonesia. Jurnal Teknologi Informasi Dan Ilmu Komputer, 5(4), 427. https://doi.org/10.25126/jtiik.201854773

[10]Riani, A., Susianto, Y., \& Rahman, N. (2019). Implementasi Data Mining Untuk Memprediksi Penyakit Jantung Mengunakan Metode Naive Bayes. Journal of Innovation Information Technology and Application (JINITA), 1(01), 25-34. https://doi.org/10.35970/jinita.v1i01.64

11]S A, S. (2021). Comparative Study of Naive Bayes, Gaussian Naive Bayes Classifier and Decision Tree Algorithms for Prediction of Heart Diseases. International Journal for Research in Applied Science and Engineering Technology, 9(3), 475-486. https://doi.org/10.22214/ijraset.2021.33228

[12]Deka, D. (2020). Detection of Congestive Heart Failure using Naive Bayes Classifier. International Journal of Engineering and Advanced Technology (IJEAT), 9(3), 4154-4159. https://doi.org/10.35940/ijeat.c6623.029320

[13]Perbawawati, A. A., Sugiharti, E., \& Muslim, M. A. (2019). Bayes Theorem and Forward Chaining Method On Expert System for Determine Hypercholesterolemia Drugs. Scientific Journal of Informatics, 6(1), 116-124. https://doi.org/10.15294/sji.v6i1.14149

[14] Silahudin, D., Henderi, \& Holidin, A. (2020). Model Expert System for Diagnosis of Covid-19 Using Naive Bayes Classifier. IOP Conference Series: Materials Science and Engineering, 1007, 012067. https://doi.org/10.1088/1757-899x/1007/1/012067

[15] Marathe, N., Gawade, S., \& Kanekar, A. (2021). Prediction of Heart Disease and Diabetes Using Naive Bayes Algorithm. International Journal of Scientific Research in Computer Science, Engineering and Information Technology, 447-453. https://doi.org/10.32628/cseit217399

[16]Ervinaeni, Y., Hidayat, A. S., \& Riana, E. (2019). Sistem Pakar Diagnosa Gangguan Hiperaktif Pada Anak Dengan Metode Naive Bayes Berbasis Web. Jurnal Media Informatika Budidarma, 3(2), 90. https://doi.org/10.30865/mib.v3i2.1158

[17]Ertuncay, D., \& Costa, G. (2021). Determination of near-fault impulsive signals with multivariate naïve Bayes method. Natural Hazards, 108(2), 1763-1780. https://doi.org/10.1007/s11069021-04755-0

[18]Putra, D. W. T., Utami, A. O., Minarni, \& Swara, G. Y. (2019). Accuracy Level of Diagnosis of ENT Diseases in Expert System. Jurnal KomtekInfo, 6(2), 127-134. https://doi.org/10.35134/komtekinfo.v6i2.51 